\title{
Flexibility Enhancement in an Islanded Distribution Power System by Online Demand-Side Management
}

\author{
Margarita Chulyukova ${ }^{1}$, Nikolai Voropai $^{2}$ \\ ${ }^{1}$ Far-Eastern Distribution Company, 32 Shevchenko Str., 675000, Blagoveshchensk, Russia, margarita_kaigor@inbox.ru \\ ${ }^{2}$ Melentiev Energy Systems Institute, 130 Lermontov Str., 664033 Irkutsk, Russia, voropai@ isem.irk.ru
}

\begin{abstract}
The paper considers the possibilities of increasing the flexibility of power distribution systems by real-time load management. The principles of the implementation of special automatic systems for this purpose are proposed. These systems enable some loads of specific consumers of the power distribution system switched to islanded operation to "shift" from the daily maximum to the minimum, which makes some generators available to connect certain essential consumers disconnected earlier by under-frequency load shedding system to the power system. The approach under consideration is illustrated by a power system with distributed generation.
\end{abstract}

\section{Introduction}

In recent decades, almost all countries in the world have been actively developing distributed generation (DG) based on various types of plants. Priorities in the use of certain technologies are determined by specific conditions $[1$, etc.]. In Russia, an important line of studies on centralized power supply focuses on the construction of mini-CHP plants using small gas turbine, gas piston, steam turbine, and other power generating units operating at a frequency of $50 \mathrm{~Hz}$ and connected to the distribution network of the power system (PS). These CHP plants are to replace obsolete uneconomical boiler houses $[2,3]$ in cities and urban-type settlements.

In many cases, the considered power systems with DG are deficient and receive the required electricity from an external grid. Such a situation can occur both in the heating period when the mini-combined heat and power plants operate at full heat and electricity load, and in the summer when their load is reduced. In the event of an emergency disconnection of the main substation from the grid, power shortage will arise in the power system. This shortage causes an emergency transient process, which triggers the operation of under- frequency load shedding (UFLS) systems to disconnect non-essential consumers. As a result, the power system operates in an emergency mode depending on the following specific conditions, given the speed governor operation:

- at rated frequency, if the load connected to the UFLC is sufficient to provide a balance between generation and consumption;

- at a lower frequency, if the load connected to the UFLC is insufficient to restore the balance, but the lower frequency lies within the permissible limits;

- at power supply shutdown, if a generation shortage remains too large.

An important objective in the considered situations of switching power system to islanded operation is to study transient and post-emergency conditions of such a system, first of all, in the process of the power system islanding, as well as at the end of this process in the post-emergency conditions [4 - 7, a.o.]. Of interest are the first two emergency development options. An important task of such research is to minimize the number of consumers to be disconnected due to an emergency.

The principal possibility of accomplishing this task may be real-time load management. In a general approach to load management, the problems solved in real-time for different purposes play an important role [8-12, a. o.]. The moment of an emergency shutdown of the main substation and the switch of the power system to the islanded operation is unexpected, and the severest postemergency situation occurs at the time of daily peak load. In this regard, the automatic shift of some power consumers by the load management system from the maximum load to the minimum one will provide electricity to consumers disconnected by UFLC during the peak load and, if necessary, increase the postemergency frequency level.

The structure of the subsequent part of the paper is as follows. Section 2 presents the components of the research methodology and the applied model of the power grid dynamics. Section 3 focuses on a description of the studied power system with DG and an analysis of the results of computational experiments. The conclusions are briefly presented at the end of the paper.

\section{Object for simulation}

An object of the research is a power system scheme built based on a modified power system in the town of Blagoveshchensk, which includes (see Fig. 1):

a $220-110 \mathrm{kV}$ substation, which connects the investigated power system with an external grid and is represented by the infinite buses in the calculations of transient processes; 
- a base CHP (BCHP) plant, which consists of four units with a total installed capacity of 404 MW (Table 1);

four mini-CHP plants with gas turbine units with a rated capacity of $12 \mathrm{MW}$ each; the total capacity of all mini-CHP plants is $96 \mathrm{MW}$. These mini-CHP plants were constructed at the sites of old uneconomical boiler houses. The electrical capacity of the mini CHP plants is determined by their heat load;

- a $110 \mathrm{kV}$ electrical network.

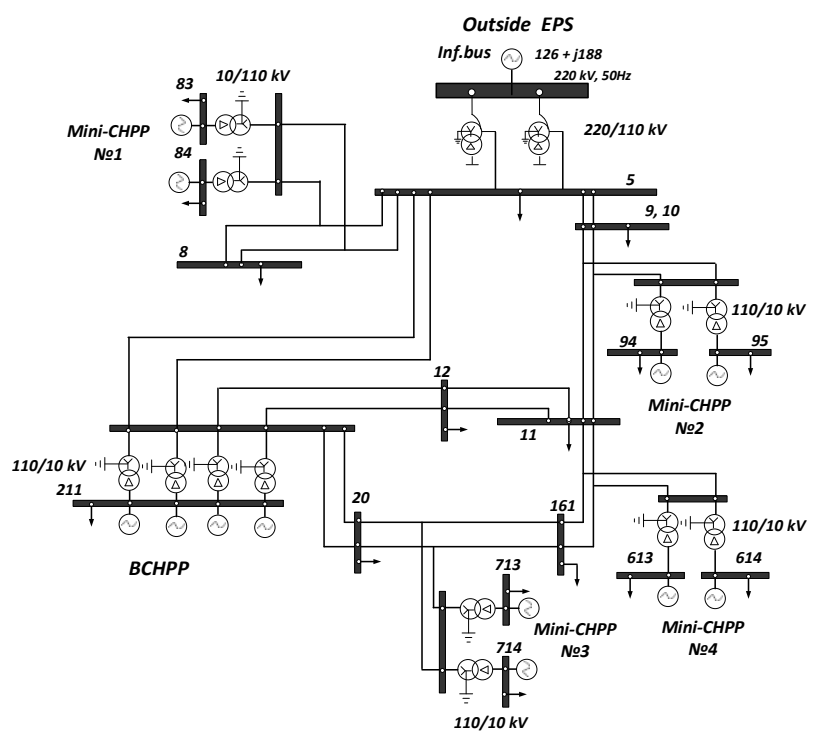

Fig. 1. Test power system

Table 1. Main parameters of synchronous generators

\begin{tabular}{|c|c|c|c|c|c|}
\hline \multicolumn{6}{|c|}{ Parameters of generators (see Figure 1) } \\
\hline & \multicolumn{4}{|c|}{ ВCHРP } & mini- \\
\hline & $\begin{array}{c}\text { GTU- } \\
1 \\
\end{array}$ & $\begin{array}{c}\text { GTU- } \\
2 \\
\end{array}$ & $\begin{array}{c}\text { GTU- } \\
3 \\
\end{array}$ & $\begin{array}{c}\text { GTU- } \\
4\end{array}$ & Nos.1-4 \\
\hline $\begin{array}{l}\text { Pnom, } \\
\text { MW }\end{array}$ & 60 & 110 & 110 & 124 & 24 \\
\hline$M j$, MWs & 182.4 & 282.7 & 282.7 & 554.3 & 65 \\
\hline$X^{\prime} d$, p.u. & 0.27 & 0.26 & 0.26 & 0.26 & 0.24 \\
\hline$X q$, p.u. & 0.83 & 1.19 & 1.19 & 1.34 & 1.9 \\
\hline$T^{\prime} d 0, \mathrm{~s}$ & 5 & 5 & 5 & 5 & 5 \\
\hline
\end{tabular}

The studies were performed using RusTab software [12]. To connect a generator to the network, $\left(E^{\prime} q, 0\right)$ was used as a rated EMF (equal to 0 on axis $d$ ) and $\left(X^{\prime} d, X q\right)$ were used as rated resistances. The voltage on the miniCHP plant buses is regulated by the excitation systems based on voltage deviation on the power plant buses. The excitation regulation at the CHP plant generators was carried out using the voltage deviation on the buses, the derivative of the voltage, the frequency deviation, the derivative of the frequency, and rotor current.

The electric power consumers of the considered power system are household and industrial loads. Given the structure of consumers, various components of the load were presented for the entire system according to [14] as follows: $50 \%$ - steady-state load-voltage characteristics (second-degree polynomial) and load-frequency characteristics (first-degree polynomial); 30\% asynchronous motors; and 20\% - synchronous motors. An individual load composition is presented for each node. The load values at the nodes shown in Fig. 1 are indicated in Table 2.

Table 2. Load at the nodes shown in the test diagram

\begin{tabular}{|c|c|c|c|c|c|}
\hline \multicolumn{7}{|c|}{ Nodes (Figure 1) } \\
\hline $\begin{array}{c}\text { Number } \\
\text { of node }\end{array}$ & $\begin{array}{c}\text { P, } \\
\text { MW }\end{array}$ & $\begin{array}{c}\text { Q, } \\
\text { MVar }\end{array}$ & $\begin{array}{c}\text { Number } \\
\text { of node }\end{array}$ & $\begin{array}{c}\text { P, } \\
\text { MW }\end{array}$ & $\begin{array}{c}\text { Q, } \\
\text { MVar }\end{array}$ \\
\hline 5 & 50 & 20 & 85 & 1 & 0.8 \\
\hline 9 & 7 & 1.5 & 94 & 1 & 0.8 \\
\hline 10 & 7 & 1.8 & 95 & 1 & 0.8 \\
\hline 11 & 50 & 20 & 613 & 1 & 0.8 \\
\hline 12 & 70 & 27 & 614 & 1 & 0.8 \\
\hline 20 & 60 & 20 & 713 & 1 & 0.8 \\
\hline 80 & 8 & 4 & 714 & 1 & 0.8 \\
\hline 84 & 1 & 0.8 & 211 & 28 & 23 \\
\hline
\end{tabular}

Fig.2 demonstrates a summer daily peak load curve for the power system.

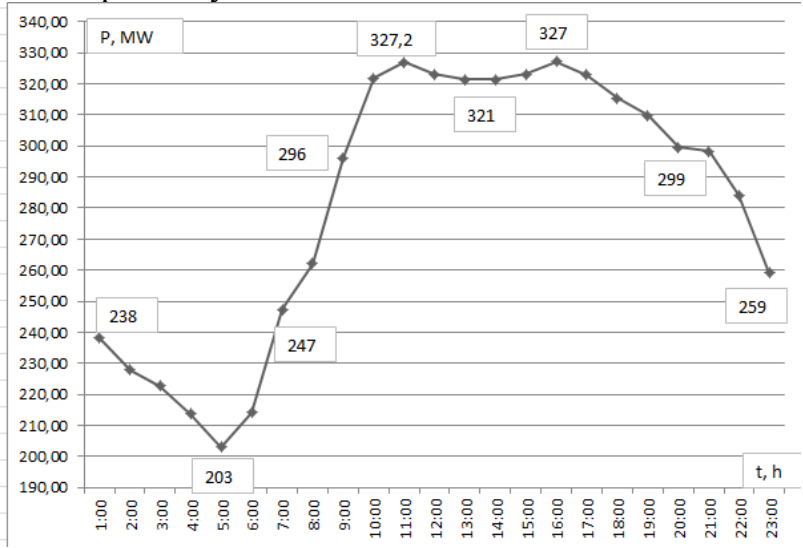

Fig. 2. Summer daily peak load curve in the power system

\section{Simulation results}

The simulated scenario for switching the power system to the islanded operation is as follows. The considered daily maximum load of a summer working day is 327.2 MW. Two units of Blagoveshchensk combined heat and power plant (GTU-2 and GTU-3) are under repair. The units of mini-CHP plant operate at rated load. The electric power required to cover the load in the preemergency conditions is supplied from an external power grid.

Due to the false operation of protection devices at the $220-110 \mathrm{kV}$ substation, the $110 \mathrm{kV}$ circuit breakers of 
the lines connecting the power system with the external power grid shut off. As a result, the power system is switched to islanded operation with a power shortage of about $38 \%$ of the total consumption. By way of illustration, Fig. 3 shows the dynamics of changes in voltage and power of the load at one of the power system nodes. The dynamics was obtained from the calculation of the transient process. At time $0.5 \mathrm{~s}$, the power system was switched to the islanded operation with power shortage of $126 \mathrm{MW}$ and a sharp decrease in voltage at a node. According to [13], when the voltage at node decreases below $75 \%$, the steady-state load characteristics are replaced by $\mathrm{PL}=$ const. and $\mathrm{QL}=$ const. Therefore, the power consumption at the node decreased from 50 to $30 \mathrm{MW}$. The frequency reached the first set point of UFLS, which operated in $1.5 \mathrm{~s}$, disconnecting $10 \%$ of the secondary load. The voltage level partially recovered, which, following the steady-state load voltage characteristic, increased power consumption by the load up to $43 \mathrm{MW}$. At time $1.8 \mathrm{~s}$, the second phase of the UFLS disconnected $20 \%$ more load in the system. As a result, at $2.0 \mathrm{~s}$, the power consumed by the load at the node, given the influence of steady-state load voltage characteristic, as well as excitation regulators of generators at power plants, and other components of the diagram, reached about 36 MW.

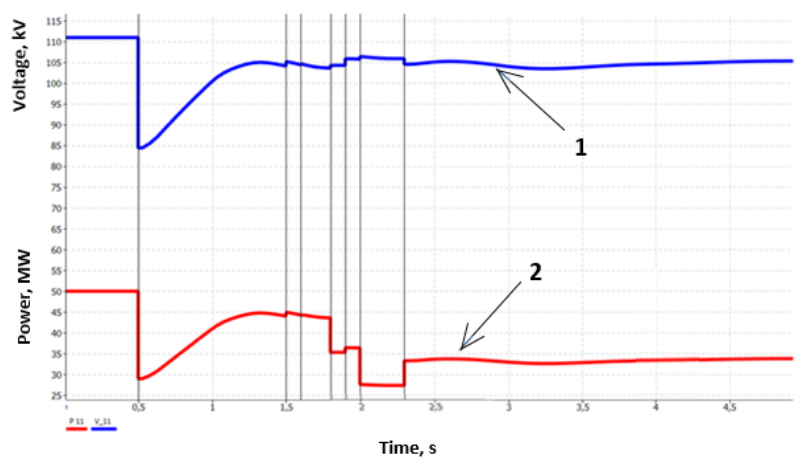

Fig. 3. Dynamics of changes in voltage (1) and power (2) consumption of the load at node

At time $2.0 \mathrm{~s}$, additional real-time load management systems operate, "shifting" some loads with a total power of approximately $9 \mathrm{MW}$ to the minimum load-interval on the curve. In $2.3 \mathrm{~s}$, the same systems connect previously disconnected consumers with a power of about $6 \mathrm{MW}$.

With this action, the operation of UFLS and additional load management systems finished and the power consumed by the load at the node approached 36 MW. After some oscillations, the frequency was approximately $49.8 \mathrm{~Hz}$ (Fig. 4).

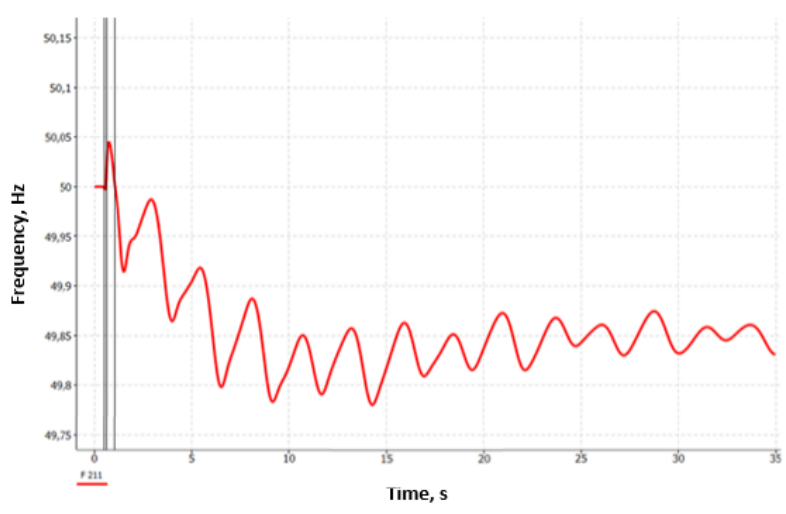

Fig. 4. System frequency dynamics

\section{Conclusion}

Real-time load management is an effective way to increase the flexibility of power systems with the distributed generation when the system is switched to the islanded operation. The paper focuses on the basic principles of implementing a new load management system. The studies carried out using the power system with distributed generation have demonstrated that the shift of the maximum load to the minimum one enables the restoration of power supply to some of the essential consumers disconnected by under-frequency load shedding system. The assessment of the dynamics of changes in load and frequency showed the significance of considering load structure for the study with corresponding models and characteristics of the load.

\section{Acknowledgment}

The work was supported by the Russian Scientific Foundation, project \#19-49-04108

\section{References}

[1] Pecas Lopes J.A., Hatziargyriou N., Mutale J., Djapic P., Jenkins N., "Integrating distributed generation into electric power systems: A review of drivers, challenges and opportunities", Electric Power System Research, 2007, Vol. 77, No. 9, pp. 1189 - 1203.

[2] Stennikov V.A., "Distributed energy generation: mission, situation, opportunities", Energy: Economics, Technology, Ecology, 2016, No. 1, p. 2-10.

[3] Stennikov V.A., "Distributed energy generation: barriers, trends, forecasts", Energy: Economics, Technology, Ecology, 2016, No. 2, p. 2 - 8.

[4] Gurevich Yu.E., Ilyushin P.V., Features of the calculation of operating conditions in load centers with distributed generation, Nizhny Novgorod, RANEPA, 2018, 280 p.

[5] Ilyushin PV, "Possibilities of providing reliable power supply to consumers of the first reliability category (including a special group) in an islanded mode from distributed generation facilities", Methodological issues of studying the reliability of large energy systems. Issue 66, Minsk, BNTU, 2018, p. 147 - 153.

[6] Kontis E.O., Kryonidis G.C., Nousdilis A.I., Malamaki K.-N.D., Papagiannis G.K., "Power flow 
analysis of islanded AC microgrids", IEEE Power Tech, Milan, Italy, June $23-27,2019,6$ p.

[7] Roos M.H., Nguyen P.H., Morren J., Slootweg J.G., "Modeling of distributed energy resources for simulating fault-initiated islanding of microgrids", IEEE Power Tech, Milan, Italy, June $23-27,2019,5$ p.

[8] Van der Kam M., Van Sark W., "Smart charging of electric vehicles with photovoltaic power and vehicle-togrid technology in a microgrid: Case study", Applied Energy, 2015, Vol. 152, pp. $20-30$.

[9] Di Giorgio A., Pimpinella L., "An event-driven smart home controller enabling consumer economic saving and automated demand-side management", Applied Energy, 2012, Vol. 96, pp. $92-103$.

[10] De Craemer K., Vandael S., Claessens B., Deconinck G., "An event-driven dual coordination mechanisms for demand-side management of PHEVs", IEEE Trans. on Smart Grid, 2014, Vol. 5, No. 2, pp. 751 -760 .

[11] Hong S.H., Yu M., Huang X., “A real-time demand response algorithm for heterogeneous devices in buildings and homes", Energy, 2015, Vol. 80, pp. 123 - 132.

[12] Yang X., Zhang Y., He H., Ren S., Weng G., "Realtime demand-side management for a microgrid considering uncertainties", IEEE Trans. on Smart Grid, 2019, Vol. 10, No. 3, 3401 - 3414.

[13] User guide of the Rustab software [electronic resource]. www.rastrwin.ru

[14] Gurevich Yu.E., Libova L.E., Okin A.A. Calculations of stability and emergency control in power systems. Moscow, Energoatomizdat, 1990, 178 pp. 